\title{
ROTEIRO GUIA: UMA EXPERIÊNCIA EM ESPAÇOS NÃO FORMAIS PARA O ENSINO DE BOTÂNICA NA REGIÃO AMAZÔNICA
}

Terezinha de Jesus Reis Vilas Boas ${ }^{\text {a }}$

Marciléa Silva de Freitas ${ }^{\mathbf{b}}$

Marta Maria Pontin Darsiếc

\section{A R T I CLE I N F O}

\section{Palavras chave:}

Espaços não-formal;

Roteiro;

Região Amazônica.

E-mail:

a terezinhajesusvb@gmail.com

b marcisilvafreitas@gmail.com

C marponda@uol.com.br

\section{R E S U M O}

O ensino de Botânica trata de um dos ramos da Biologia que possibilita a formação científica do indivíduo promovendo o reconhecimento e valorização de espécies regionais. Propostas de ensino na região Amazônica com este enfoque podem proporcionar aprendizagem significativa que irão repercutir diretamente em um novo olhar para os elementos da floresta. Conforme preconizam os PCNs o ensino deve permear atividades práticas. E Esteves (2011) acrescenta que a Botânica é uma ferramenta fundamental para a compreensão de alterações ambientais considerando que as plantas formam o maior componente dos ecossistemas. Assim o presente estudo objetivou verificar como alunos no Curso de Formação de Licenciatura em Ciências Biológicas do Instituto Federal de Educação, Ciência e Tecnologia do Amazonas - IFAM percebem as relações entre Botânica e Meio Ambiente. A metodologia utilizada baseou-se numa pesquisa de campo, com objetivo de aprimoramento das ações coletivas no campo pedagógico, subsidiando os aspectos inovadores da autorreflexão e o alcance de uma intervenção significativa para a vivência e formação dos envolvidos na pesquisa. A visita de campo permitiu dar subsídio aos alunos, sobre a importância dos espaços não formais como estratégia de ensino e destaca a importância do roteiro como instrumento norteador para as atividades de aulas práticas.

\section{INTRODUÇÃO}

O ensino de Botânica desenvolvido nas escolas precisa ser refletido a partir de uma abordagem em que o aluno consiga interligar os conhecimentos teóricos adquiridos sobre as plantas com as discussões relativas aos problemas ambientais vividos no planeta Terra. Temas sobre meio ambiente são amplamente debatidos na mídia na busca de uma consciência sustentável. Para a garantia de uma relação sustentável a partir dos conhecimentos construídos na escola, colocou-se como estratégia o papel da Botânica nos processos de compreensão das influências que as plantas exercem no ambiente, impedindo ações de degradação, bem como 
auxiliando na construção de valores, ações mais responsáveis, habilidades exigentes nos contextos atuais, e competências para saber lidar com a conservação do meio ambiente.

De acordo com os Parâmetros Curriculares Nacionais (PCNs), nas ciências naturais e biológicas da educação contemporânea, o conhecimento científico é fundamental, mas não suficiente, não devendo estar restrito somente a conceitos, mas antes, possibilitar o acesso à observação e à percepção do mundo real. É essencial considerar o desenvolvimento cognitivo dos estudantes, relacionado às suas experiências, sua idade, sua identidade cultural e social, e os diferentes significados e valores que as ciências naturais podem ter para eles, para que a aprendizagem seja significativa (BRASIL, 1999).

Nessa perspectiva, a floresta amazônica é um espaço de composição nativa que pode funcionar como um laboratório vivo para o desenvolvimento de atividades de ensino e de pesquisa. Os elementos bióticos como as árvores, os animais, os fungos e os elementos abióticos como a água presente nos rios e riachos, o solo podem se constituir em recursos pedagógicos para o Ensino de Ciências e Biologia (ARAÚJO; SILVA, 2013).

Os alunos foram levados a observar, descrever e coletar imagens para perceberem a interação com os vegetais em cada ambiente visitado. Posteriormente foi feito uma discussão em sala para constatação da aprendizagem, onde os alunos puderam demonstrar a ressignificação de conceitos sobre plantas e suas inter-relações, demonstradas por meio de cartazes e ilustrações, que proporcionou aos alunos um conhecimento geral e atualizado sobre a importância de tais conteúdos para o ensino da botânica e a formação da concepção ambiental.

Assim, práticas de ensino diferenciadas têm contribuído consideravelmente para uma mudança de postura em relação aos conhecimentos botânicos, numa visão conciliadora no que inclui o estudo dos ambientes naturais, os impactos humanos sobre o ambiente e as medidas tomadas para reduzi-los (ESTEVES, 2011).

\section{METODOLOGIA}

O presente estudo foi desenvolvido na Reserva Biológica da Campina/Campinarana, pertencente ao Instituto Nacional de Pesquisas da Amazônia (INPA) apresentando uma área de 900 ha, localizada no $\mathrm{km} 44$ da BR-174 (02³5 S e 60 $\left.02^{`} \mathrm{~W}\right)$. 


\section{REVISTA REAMEC}

Revista da Rede Amazônica de Edureação em Ciências e Matemática
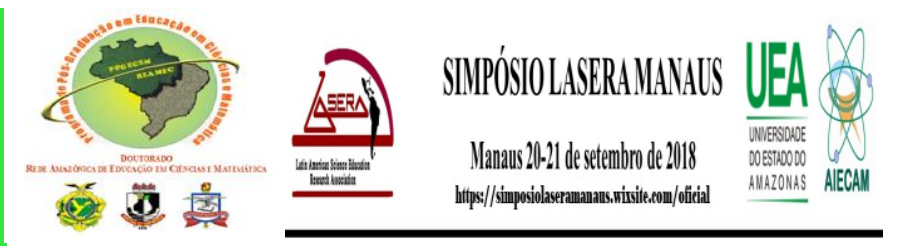

Aula de campo nos ambientes não formais em Presidente Figueiredo: Os alunos das disciplinas de Vegetais Superiores no total de (07), Fisiologia Vegetal no total de (07) e do Segundo Período no total de (06) do curso de Licenciatura em Ciências Biológicas participaram da aula de campo.

Uso do Roteiro de Campo: Com o intuito de construir uma rota onde os alunos sujeitos da pesquisa pudessem observar nos espaços não formais os elementos essenciais para processos de aprendizagem quanto ao tema abordado, utilizou-se o roteiro de campo, demonstrando a importância dele nos processos de ensino, como forma de organizar as estratégias das aulas de campo, no alcance dos objetivos. O roteiro, se seguido, garante a execução das ações pretendidas (Quadro 1).

A prática de campo deve ser feita a partir de um roteiro que contemple os objetivos a serem alcançados, direcionando os alunos quanto ao reconhecimento do tipo de local, relação das plantas com o espaço para que os mesmos saibam relacionar os conhecimentos teóricos de sala com os visualizados no lugar visitado.

Quadro1: Roteiro de campo para a realização das aulas campo

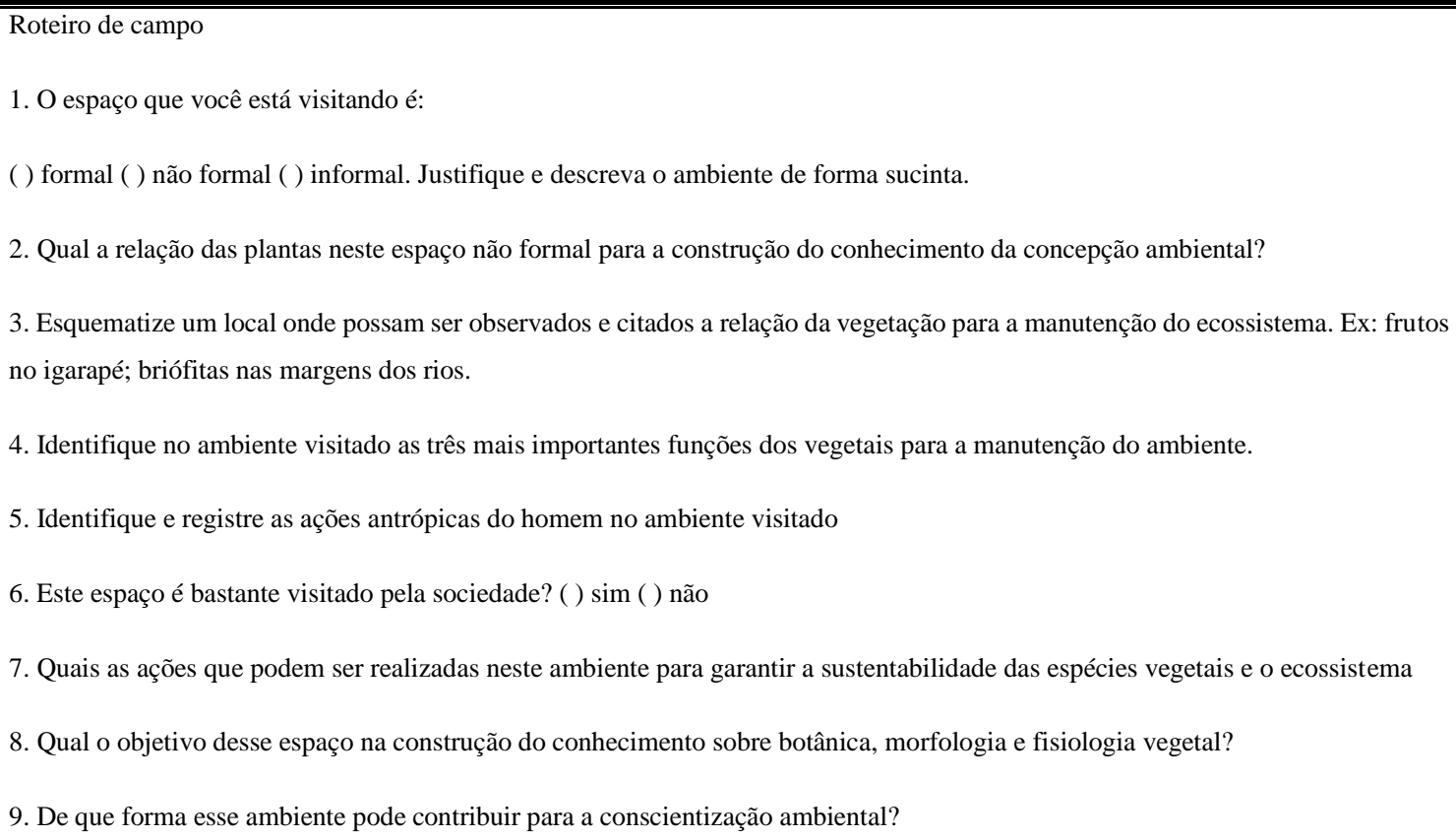




\section{REVISTA REAMEC}

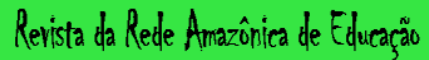

em Ciências e Matemática

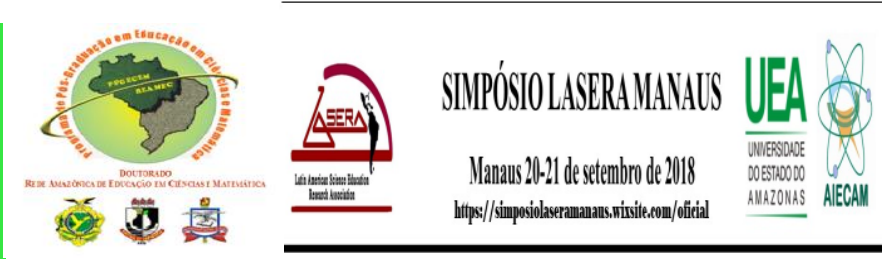

10. Registrem as suas experiências neste ambiente por meio de fotos e observações escritas em relação aos recursos naturais em forma de: a) solo b) fauna c) flora d) água e) registrar por escrito no caderno de campo localização, data e características gerais dos materiais.

12. Ressignifique um conceito em relação aos recursos naturais aproveitando o máximo de descrição espontânea, abordando a importância da preservação do(a) solo, flora e água para o ensino de botânica, morfologia e fisiologia vegetal

13. Comparar os conceitos construídos sobre espaço não formal elaborados por você com o conceito científico das literaturas

14. Verificação da aprendizagem:

a) Em sua opinião quais os ganhos observados quanto as questões de aprendizado para a ressignificação dos conceitos em relação a importância da preservação dos recursos naturais observados neste ambiente como forma de contribuir para a consciência ambiental?

b) Cite exemplos práticos que correlacionam os ensinamentos aprendidos em sala de aula sobre a importância da preservação da Amazônia com os adquiridos neste ambiente.

Fonte: Elaboração própria, 2015.

\subsection{Registros realizados nos ambientes}

Os alunos durante a visita além de seguirem o roteiro realizaram o registro com fotos e desenhos dos ambientes e observaram em cada registro as seguintes situações: 1. Importância da vegetação. 2. Principais habitats e suas variações de acordo com os ambientes. 3. A dinâmica das relações entre vegetais. 4. Tipo de vegetação. 5. Ação antrópica nos locais visitados. 6. Em cada ambiente foi sugerido observar mudanças na densidade das espécies, características morfológicas, densidade da serapilheira, presença de epífitas, briófitas, pteridófitas e líquens.

\subsection{Espaços não formais - visitados 2.2.1 Asframa}

Balneário da Associação dos Servidores da SUFRAMA - ASFRAMA localizada na BR 174, km 98.

\subsubsection{Reserva Biológica da Campina e Campinarana do INPA}

O presente estudo foi desenvolvido na Reserva Biológica da Campina/Campinarana, pertencente ao Instituto Nacional de Pesquisas da Amazônia (INPA) apresentando uma área de 900 ha, localizada no km 44 da BR-174 (02³5` S e 60 $\left.02^{`} \mathrm{~W}\right)$.

\subsection{Atividades de Verificação do Aprendizado - Socialização}


Ao final das atividades foi realizada uma socialização com os alunos por meio de discussão, confecção de cartazes, e apresentação em sala, como forma de avaliar as atividades e aspectos positivos quanto à prática realizada nos ENFs.

\section{RESULTADOS E DISCUSSÃO \\ 3.1 Relatos dos alunos em relação aos ambientes visitados}

Nesta atividade de campo com os alunos do $2^{\circ}, 6^{\circ}$ (morfologia vegetal) e $8^{\circ}$ (Fisiologia vegetal) do curso de Licenciatura em Ciências Biológicas informaram que a atividade campo nos espaços não formais promoveu motivação e permitiu consolidar conhecimentos tratados em sala de aula que possuíam exemplos que não eram regionais.

O uso do roteiro (guia) surge como proposta para o desenvolvimento da prática interligando conhecimento botânico com as questões ambientais. A compreensão do ambiente só pode ser realizada com o conhecimento sobre os componentes do ambiente e seu real papel para a natureza.

Para a respectiva aula, cada aluno pôde "descrever o ambiente de acordo com suas concepções”. Dentre as observações realizadas sobre os ambientes foram relatadas:

Quadro 2 - Qual a relação das plantas neste espaço não formal para a construção do conhecimento da concepção ambiental?

\begin{tabular}{|c|c|}
\hline TURMAS & RESPOSTAS DOS DISCENTES \\
\hline MV & $\begin{array}{l}\text { "Devido à diversidade que elas têm na floresta, demonstram a biodiversidade da Amazônia". (aluno } \\
\text { 1) }\end{array}$ \\
\hline MV & "É uma floresta que está fora do meio urbano, um lugar natural". (aluno 3) \\
\hline FV & "Mostra a condição do clima natural da Amazônia". (aluno 5) \\
\hline FV & $\begin{array}{l}\text { "Neste local, é possível se observar características de interações das plantas com o ambiente } \\
\text { preservado, livre da ação humana". (aluno 2) }\end{array}$ \\
\hline FV & $\begin{array}{l}\text { "Justifica a importância de se preservar o meio ambiente para a manutenção da vida através das } \\
\text { interações". (aluno 4) }\end{array}$ \\
\hline MV & $\begin{array}{l}\text { "O ambiente preservado sem alterações provocadas pela ação do homem, conserva os padrões de } \\
\text { temperaturas e, por conseguinte os padrões de clima". (aluno 9) }\end{array}$ \\
\hline FV & "mostra a diversidade de plantas da Amazônia". (aluno 10) \\
\hline MV & "mostra a importância das matas no controle do clima". (aluno 11) \\
\hline FV & “de relação positiva e ativa quanto à forma de absorção de água e interação com o solo". (aluno 15) \\
\hline MV & "Identificação de tipos de plantas, lugar rico para coletas de material para estudos". (aluno 13) \\
\hline FV & $\begin{array}{l}\text { "O ambiente bem preservado pode fazer com que a relação fauna, flora e clima funcionem } \\
\text { corretamente". (aluno 19) }\end{array}$ \\
\hline MV & "Podemos observar as plantas de diversos tipos, observei a borda das plantas". (aluno 1) \\
\hline $2^{\circ}$ Período & $\begin{array}{l}\text { “A contextualização dos vegetais com o ambiente sendo utilizado em estudos e pesquisas". (aluno } \\
20 \text { ) }\end{array}$ \\
\hline FV & "Estudo científico para análise das mudanças".. (aluno 8) \\
\hline MV & "Há uma relação de tentativa de conservação do meio ambiente" (aluno 10) \\
\hline MV & "O objetivo é ir além dos livros, é entrar em contato". (aluno 2) \\
\hline MV & "mostrar a condição do clima natural". (aluno 7) \\
\hline
\end{tabular}

Fonte: Roteiro (questão 2).

Revista REAMEC, Cuiabá - MT, V. 6, n. Especial, dez 2018, ISSN: 2318-6674

Revista do Programa de Doutorado da Rede Amazônica de Educação em Ciências e Matemática

http://periodicoscientificos.ufmt.br/ojs/index.php/reamec 


\section{REVISTA REAMEC}

Revista ta Rede Amazonitica de Eduraçăo em Ciêneias e Matemática
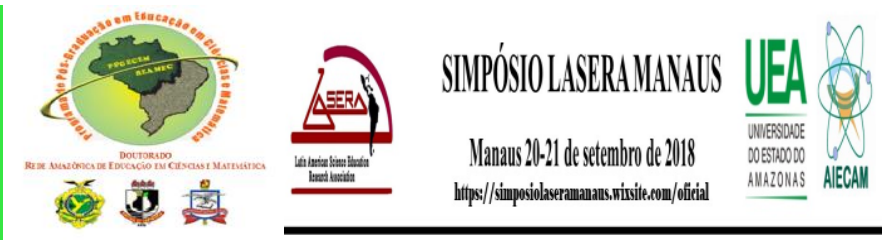

Pelos relatos do (quadro 2) é possível perceber que os alunos conseguem identificar os elementos que compõem a floresta e a importância da manutenção da vegetação.

\subsection{Os Espaços não-formais como estratégia para o Ensino de Botânica 3. 2.1 Asframa}

Balneário da Associação dos Servidores da SUFRAMA - ASFRAMA localizada na BR 174, km 98. Fundada em 21/05/1979, é uma sociedade civil de direito privado, sem fins lucrativos, de duração indeterminada, com sede e foro na cidade de Manaus, na Av. Governador Danilo Areosa $n^{\circ}$ 100, Distrito Industrial. Tem como objetivo promover a interação e o bemestar dos servidores da SUFRAMA, através de atividades sociais, artísticas, culturais, recreativas, desportivas e desenvolver outras atividades compatíveis com a natureza da Associação.

A ASFRAMA é caracterizada por uma formação arbustiva arbórea marcada por clareiras estabelecidas pela ação antrópica com a finalidade de desenvolver atividades de lazer. Em se tratando de um ambiente banhado por nascentes, estas áreas são ricas em vegetais classificados como criptógamas (órgãos reprodutivos não visíveis) por sua dependência por água. Além disso, são frequentes as demais associações como líquens e fungos compondo a vegetação.

É um local formado por um circuito de águas que formam corredeiras e alguns pontos apresentam quedas d'águas formando pequenas cachoeiras sendo utilizados como ponto de diversão para a sociedade (Figura 1). O Instituto Federal de Educação Ciência e Tecnologia do Amazonas tem contado com a disponibilidade do espaço para visitas a campo sempre que solicitado à secretaria da ASFRAMA. Trata-se de um ambiente ideal para se observar a colonização das briófitas, pteridófitas, angiospermas, líquens e fungos.

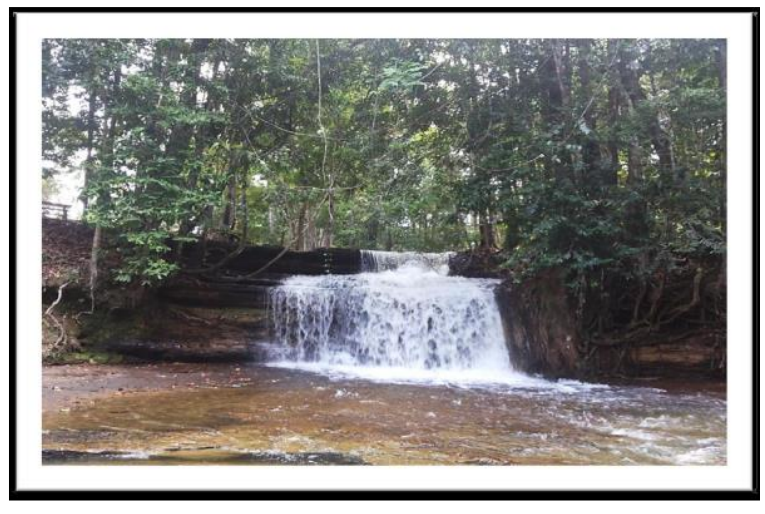

Revista REAMEC, Cuiabá - MT, V. 6, n. Especial, dez 2018, ISSN: 2318-6674

Revista do Programa de Doutorado da Rede Amazônica de Educação em Ciências e Matemática http://periodicoscientificos.ufmt.br/ojs/index.php/reamec 
Figura 1 - Cachoeira principal da ASFRAMA cercada de vegetais superiores e com a predominância de briófitas, liquens, fungos e algas.

Fonte: Vilas Boas.

No espaço visitado da Cachoeira da Asframa, conforme a (figura 2), foi possível visualizar uma paisagem exuberante, onde os sujeitos da pesquisa puderam observar elementos peculiares de cada lugar. As raízes sobrepostas, a morfologia das folhas, tipos de vegetação e o igarapé com água de uma coloração escura completaram o cenário, livre de ações antrópicas.

Ao destacar o tópico - água - sem dúvida um tema importante para se discutir com os discentes em estudos como vida, saúde, meio ambiente, química e física, por exemplo, sem essa fragmentação do ensino, pois a água é o composto essencial para a vida, correspondendo a 70\% da composição celular. Portanto, suas propriedades físicas e químicas são essenciais para a vida; a poluição pode levar a problemas de saúde imediatos ou futuros; os seres vivos não vivem sem água; podendo citar uma série de correlações que podem contribuir para uma melhor contextualização da importância dos elementos que compõem a natureza.

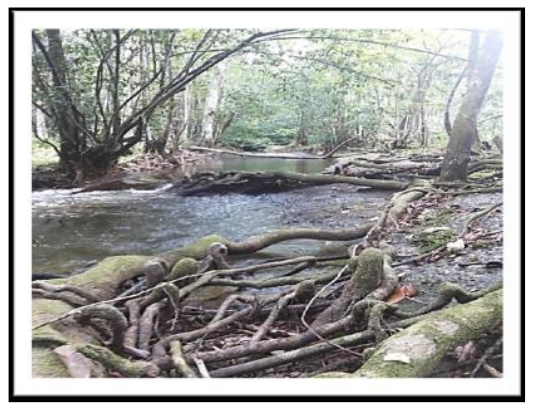

Figura 2 - Distribuição das raízes e vegetações às margens das águas.

Fonte: Villas Boas.

Conforme a (figura 2) é possível perceber a presença de briófitas no solo, evidenciando sua função no meio ambiente, como elemento fundamental para os ecossistemas. Sua função é indispensável para a natureza. Desse modo aproximando os alunos dos conhecimentos teóricos de forma prática. Tal visualização possibilitou a aquisição de conhecimento científico para os alunos público alvo da pesquisa, e ressaltou a importância das aulas práticas na aquisição da aprendizagem significativa.

\subsubsection{Reserva Biológica de Campina/Campinarana 3.2.2.1 Área de Campina}




\section{REVISTA REAMEC}

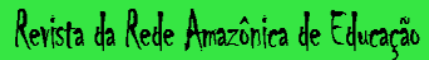
em Ciêneias e Matemática
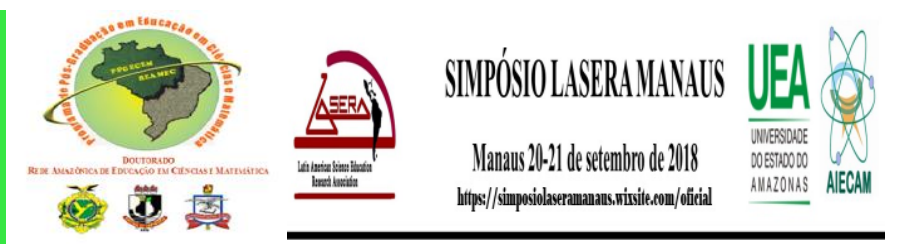

A reserva trata de um ambiente rico em biodiversidade, uma espécie de laboratório vivo, em plena floresta, caracterizando um espaço de aprendizagem que desperta para várias abordagens no ensino. A Reserva Biológica da Campina, localizada no INPA, km 44 da BR174, com tipo de formação vegetal arbustiva-arbórea-graminóide, diferente das imponentes florestas amazônicas, é caracterizada por solos arenosos da classe Espodossolo Cárbico Hidromórfico (ELIAS; AMARAL; ARAÚJO, 2007), com alta condutividade hidráulica do solo e alta infiltração da água no solo, conforme se pode ver na (Figura 3).

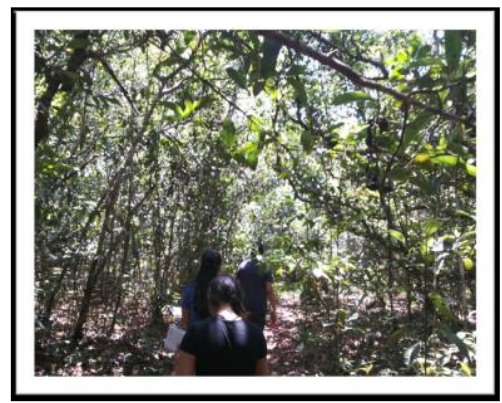

Figura 3 - Entrada da reserva biológica de campina e Campinarana.

Fonte: Vilas Boas.

\subsubsection{Campinarana}

A Campinarana tem como características árvores de até $20 \mathrm{~m}$ de altura, grande quantidade de serapilheira, poucas árvores com diâmetros maiores que $30 \mathrm{~cm}$ para melhor aproveitamento de água e nutrientes. Apresenta também o húmus verdadeiro que é a matéria orgânica resultante da decomposição (Figura 4).

Conforme Anderson, Prance e Albuquerque (1975) a Campinarana é caracterizada por apresentar uma formação vegetal mais contínua que a campina, com reduzida entrada de radiação solar, com estratificação complexa, sendo uma variação de floresta densa, estrato herbáceo quase ausente, árvores com altura máxima de 20 m, tortuosas, com lianas, epífitas (bromélias e orquídeas) e grande espessura do caule, tendo menor taxa de decomposição da 


\section{REVISTA REAMEC}

Revista ta Rete Amazônite de Edureaço em Ciênciass e Matemática
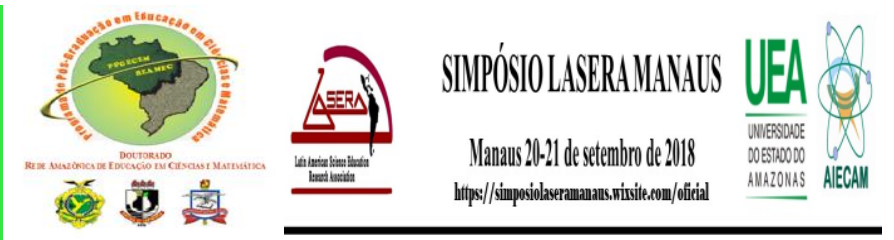

serrapilheira do que a campina, com formação de húmus verdadeiro devido a grande produção de serrapilheira.

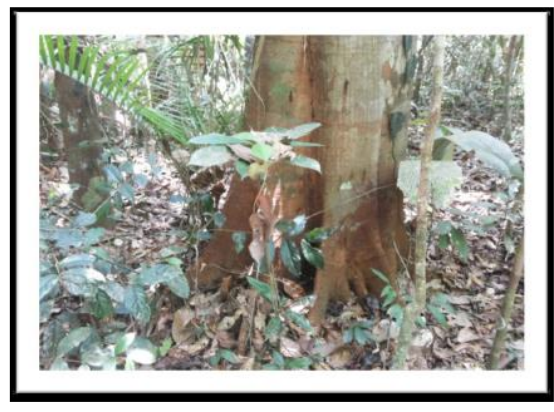

Figura 4 - Área da reserva biológica de Campinarana.

Fonte: Vilas Boas.

\subsubsection{Região Intermediária}

Entre Campina e Campinarana tem-se uma região intermediária marcada por árvores com epífitas e outras associações como líquens, briófitas, fungos e húmus (Figuras 5). Nestes ambientes se podem observar as mudanças nas morfologias da vegetação e as interações e a participação dos vegetais na ciclagem dos nutrientes.

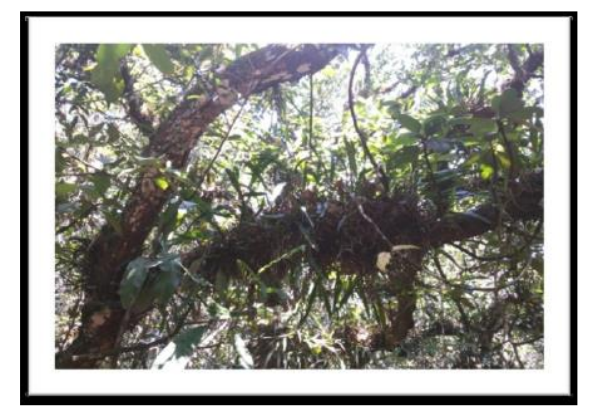

Figura 5 - Região intermediária marcada por árvores com epífitas e outras associações.

Fonte: Vilas Boas.

Nos espaços visitados de campina é possível encontrar árvores de grandes portes e diâmetros variados o que possibilita o menor acúmulo de liteira, e uma maior incidência de luz solar. Durante a visita aos diferentes ambientes foi possível observar a distribuição de várias espécies de árvores, arbustos, ervas briófitas e pteridófitas. A flora que compõe os ambientes participa dos processos fotossintéticos (Figura 6). Conforme Dias (2006) a fotossíntese é a 


\section{REVISTA REAMEC}

Revista da Rede Amazônica de Eduração

em Ciências e Matemática
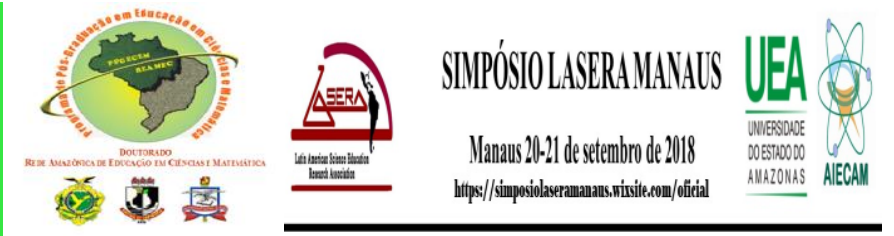

reação química mais importante do planeta. É por meio desse fenômeno que os vegetais produzem seu próprio alimento, necessário para o crescimento e a reprodução.

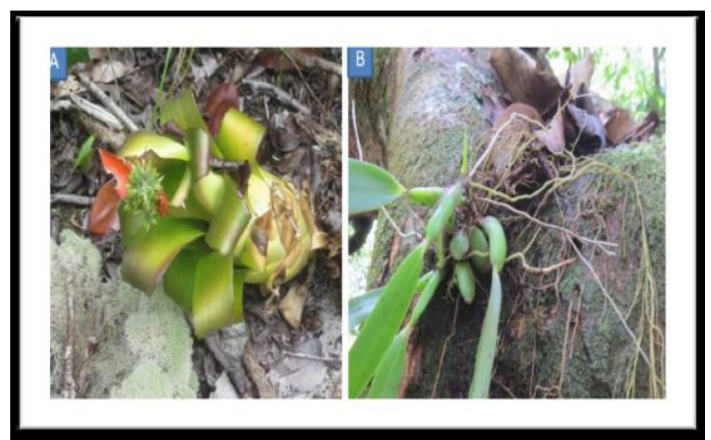

Figura 6 - A. Bromélias dispostas nos solos. B. Orquídea nos troncos de árvores.

Fonte: Vilas Boas.

Em relação às Briófitas e Pteridófitas, nos ambientes com umidade a distribuição destes grupos se faz iminente. A presença se faz devido sua dependência em relação a água. As briófitas formam um grupo ancestral das plantas terrestres, que possivelmente se originaram no período Devoniano Inferior, cerca de 400 milhões de anos atrás (GRADSTEIN; CHURCHILL; SALAZAR-ALLEN, 2001). Observou-se que os sujeitos da pesquisa puderam ter contato com esses vegetais, constatando de perto suas funções, características e importância. As briófitas exercem um papel importante no meio ambiente, pois evitam erosões e mantêm a umidade do solo.

\section{CONSIDERAÇÕES FINAIS}

O meio ambiente tem sido foco de várias discussões, principalmente pelas alterações e consequências causadas por ações antrópicas. Portanto, as discussões sobre a temática da pesquisa ressaltaram a importância do uso de espaços não formais. Uma das alternativas de compreensão da importância da conservação do meio ambiente se faz pelo papel da escola como propulsora de conscientização e visão crítica na busca de renovação dos conhecimentos, a partir de estudos mais criteriosos relacionados com esse assunto.

Os conhecimentos botânicos podem favorecer a compreensão das questões ambientais, por se tratar de uma disciplina de muita abrangência. No entanto, é necessário que o educador ressignifique suas ações no ensino, para que suas aulas estejam agregadas às questões sociais, econômicas, políticas e tecnológicas. Constatou-se que o uso dos espaços não formais deu 


\section{REVISTA REAMEC}

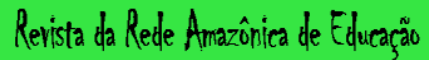

em Ciênciass e Matemática
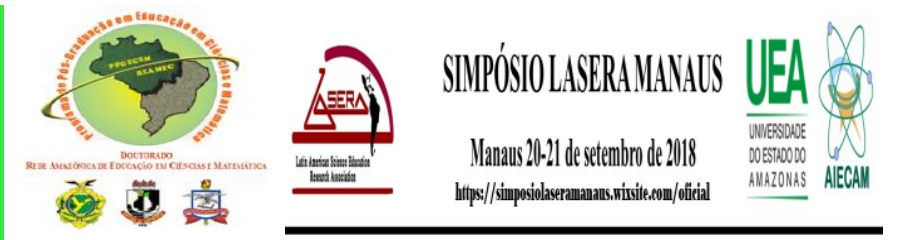

ênfase às questões ambientais, envolveu e dinamizou processos de aprendizagem, visualizando as inter-relações das plantas e os ciclos de manutenção de vida no planeta.

A difusão de conhecimento regional só é viável com o desenvolvimento de prática de campo, como exemplo, nos espaços não formais, onde os alunos conseguem ter uma compreensão direta de todos os elementos essenciais para a manutenção dos ecossistemas e de sua importância para o ambiente, como forma de ressaltar, valorizar e garantir até mesmo a sustentabilidade das riquezas naturais da região Amazônica.

\section{REFERÊNCIAS}

ARAÚJO, J. N.; SILVA, M. F. V. Floresta amazônica: espaço não-formal potencial para aprender botânica. In: CONGRESSO NACIONAL DE EDUCAÇÃO, 11, EDUCERE, 2013.

ANDERSON, A.B.; PRANCE, G.T.; ALBUQUERQUE, B.W.P. Estudos sobre a vegetação das campinas amazônicas - a vegetação lenhosa da campina da Reserva Biológica INPASUFRAMA (Manaus-Caracaraí, Km 62). Acta Amazônia, vol. 5, n. 3, p. 225-226, 1975.

BRASIL. Ministério da Educação e do Desporto. Secretaria de Educação Média e Tecnológica. Parâmetros Curriculares Nacionais: ensino médio. Brasília: Ministério da Educação, 1999.

DIAS, Filho, Moacyr Bernardino. A Fotossíntese e o Aquecimento Global. Manaus: Embrapa Amazônia Oriental, 2006.

ELIAS, D. C. N.; AMARAL, L. H.; ARAÚJO, M. S. T. Criação de um espaço de aprendizagem significativa no plenário do parque Ibirapuera. Revista Brasileira de Pesquisa em Educação em Ciências, v. 7, n. 1, 2007.

ESTEVES, L. M. Meio ambiente \& botânica. São Paulo: Editora SENAC São Paulo, 2011.

GRADSTEIN, S. R.; CHURCHILL, S. P.; SALAZAR-ALLEN, N. Guide to the Bryophytes of Tropical America. Memoirs of the New York Botanical Garden. New York, v. 86, p. 577, 2001. 